\title{
Durability in Marine Environment of High-performance Concrete with Electric arc Furnace Slags and Cupola Slag Admixture
}

\author{
Israel Sosa, Carlos Thomas, Juan Antonio Polanco, Jesús Setién and Pablo Tamayo \\ LADICIM (Laboratory of Materials Science and Engineering), University of Cantabria. E.T.S. de \\ Ingenieros de Caminos, Canales y Puertos, Av.Los Castros 44, 39005 - Santander, Spain. \\ ladicim@unican.es
}

\begin{abstract}
Obtaining new building materials that are more environmentally friendly than the traditional and that guarantee an optimal response to the most demanding conditions, is one of the greatest challenges in the science of materials. The use of electric arc furnaces slags (EAFS) and cupola slag (CS) to produce a structural self-compacting concrete (SCC), involves the valorization of industrial byproducts that often end up in landfill and avoid the extraction of a natural resource. The potential qualities of these wastes make them desirable for the production of high quality concrete. Highperformance concrete mixes are designed taking advantage of the high stiffness, the peculiar geometry and the high strength of the EAFS, as well as the high pozzolanicity of the cupola slag. There are great benefits at the mechanical level with its use, but it is necessary to know more about its durability. Different mixes using basalt aggregates and silica sand are used to compare the effects of using EAFS and cupola slag admixture in mixes that have been subjected to durability tests. These tests consist of the determination of chloride ion penetration and protection against reinforcement corrosion after 10 months of exposure in tidal race. The comparisons made after subjecting the different mixes to these tests allow to conclude that chloride ions penetrate almost twice with EAFS than with natural aggregates, while no corrosion of the bars has been shown in any of the mixes.
\end{abstract}

Keywords: Durability, EAFS, Cupola Slag, Chloride Ions Penetration, Corrosion.

\section{Introduction}

Obtaining high-performance self-compacting concrete (SCC) with EAFS is a novelty, and its durability plays an important role in its application as a structural material. As a novelty as well, it is proposed to determine its response to the chlorides penetration in a marine environment, and to check the corrosion conditions of the rebar under the same conditions.

The durability of the concrete strongly depends on the fluid circulation capacity through its microstructure, being the capillarity of the material and the paste-aggregate interfacial transition zone, the main route of penetration of external agents. One of the main causes of the deterioration of concrete are the attacks by chlorides and sulfates, and the kinetics in which the degradation mechanisms act, are related to temperature, humidity and fluid transport capacity (Ministerio de Fomento de España, 2008). Before analyzing the response of the SCC against the causes of deterioration of concrete, it is important to take into account that the microstructure of the SCC depends on factors such as the water/fines ratio, the type and content of admixtures, the type and proportion of additives or the mixing procedure (De Schutter and Audenaert, 2007).

Chlorides in concrete can come from its components, because they are totally or partially submerged in seawater or by occasional contributions on the surface, in the form of salts for thawing on roads or through salty fog due to their proximity to the coastline. 
The chloride ion penetrates the concrete pore network normally dissolved in water, one part is chemically bonded with the tricalcium aluminate of the cement to form the Friedel salt, another part is immobilized by physical bonds and the rest in the form of free chlorides in the pore solution (E. Medina, 2013). Depending on the concentration of free chlorides, pitting corrosion of the reinforcing steel rebars may occur. Additionally, when the water evaporates inside the pores, the salts crystallize generating, due to the increase in volume, internal tensions in the concrete and, consequently, cracks.

The response of the SSC against the penetration of chlorides depends on the pore structure and the ionic composition thereof. Zhu and Bartos (Zhu and Bartos, 2003) conclude that the diffusion of the chloride ion depends on the type of admixture used. Additionally, they comment that the penetration of chlorides is not less for the SCC with the same strength or manufactured with the same water/cement ratio as for a conventional vibrated concrete (CVC). Other authors have observed that chloride ion penetration decreases with the use of admixtures, especially those of a pozzolanic nature (Uysal and Yilmaz, 2011).

Thus, it is considered necessary to establish the behavior of these new SCC against aggressive environments, due to the variability on which their response depends. Four SCC mixes that incorporate natural and siderurgical aggregates will be tested, in addition to traditional and siderurgical admixtures. Reinforced concrete conical specimens of 28 days of age have been submerged for 10 months, then they were sectioned and the depth of the chlorine ion and the degree of corrosion in the reinforcement have been assessed.

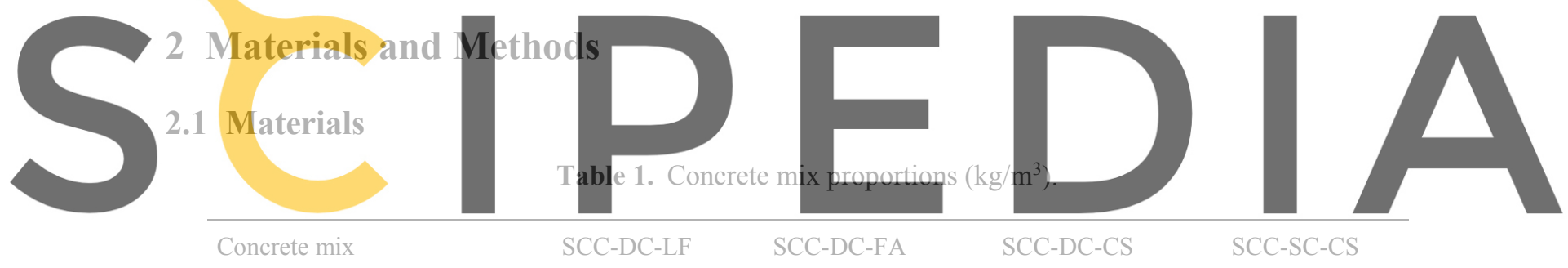

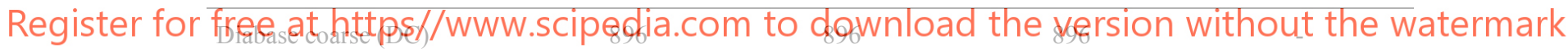

Slag coarse (SC)

Diabase sand (DS)

Silica sand (SIS)

Slag sand (SLS)

Limestone filler (LF)

Fly ash (FA)

Cupola slag filler (CS)

Cement

Water

Superplasticizer additive

$\mathrm{w} / \mathrm{c}$ ratio
411

386

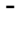

100
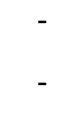

450

180

9

0.40
411

386

$-$

80

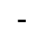

450

180

9

0.40
1101

411

386

605

444

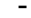

-

109

450

174

9

0.39 
Four concrete mixes have been manufactured, using CEM I $52.5 \mathrm{R}$, sand 0/6 (diabase and EAFS), coarse 6/12 (diabase and EAFS) and silica sand 0/2, to compare the behavior of the siderurgical aggregate with the natural aggregate. In addition, three different filler materials (limestone, fly ash and cupola slag) have been used. A SCC has been designed according to the procedure described by Dinakar et al. (Dinakar et al., 2013) with a 2\% (of the cement weight) of a superplasticizer additive, in a 1201 rotating drum mixer with a kneading time of $12 \mathrm{~min}$. The concrete mix proportions appear in Table 1.

\subsection{Methods}

\subsubsection{Preparation of the Specimens}

The test campaign for the characterization of the durability of hardened concrete consists of exposure to seawater of conical specimens with embedded corrugated steel bars. For the manufacture of each specimen, an Abrams cone with the face of smaller diameter as a base, has been used to facilitate filling of the specimen, following the methodology described by $\mathrm{C}$. Thomas et al. (Thomas et al., 2013). In its interior two corrugated bars of diameter $10 \mathrm{~mm}$ have been placed vertically, arranged in such a way that the minimum covering of one of the bars at the base of the cone is $10 \mathrm{~mm}$ while, in the second bar, it is $30 \mathrm{~mm}$, Figure 1.

This configuration has been designed with the objective of evaluating the protection against corrosion offered by self-compacting concrete made with coating thicknesses lower than those allows the penetration of the chloride ion to di
In Figure 1 can be seen that, in addition to
embedded in order to facilitate the manipulati
in the steel that can affect the adhesion betwe
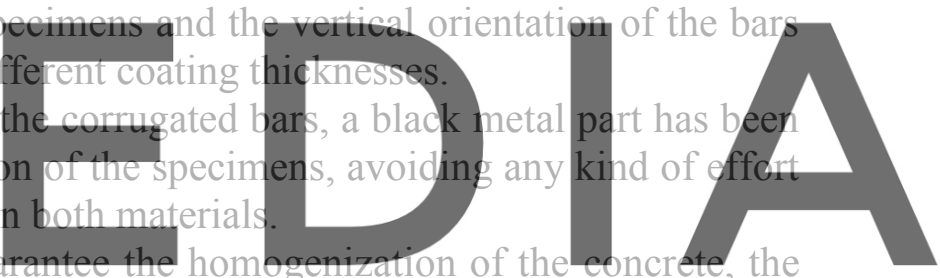

filling of the molds and the specimens has been done in a single step and without external

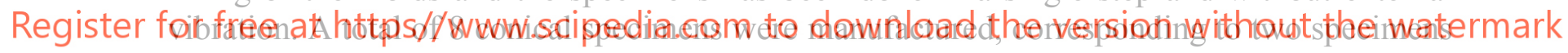
for each mix.
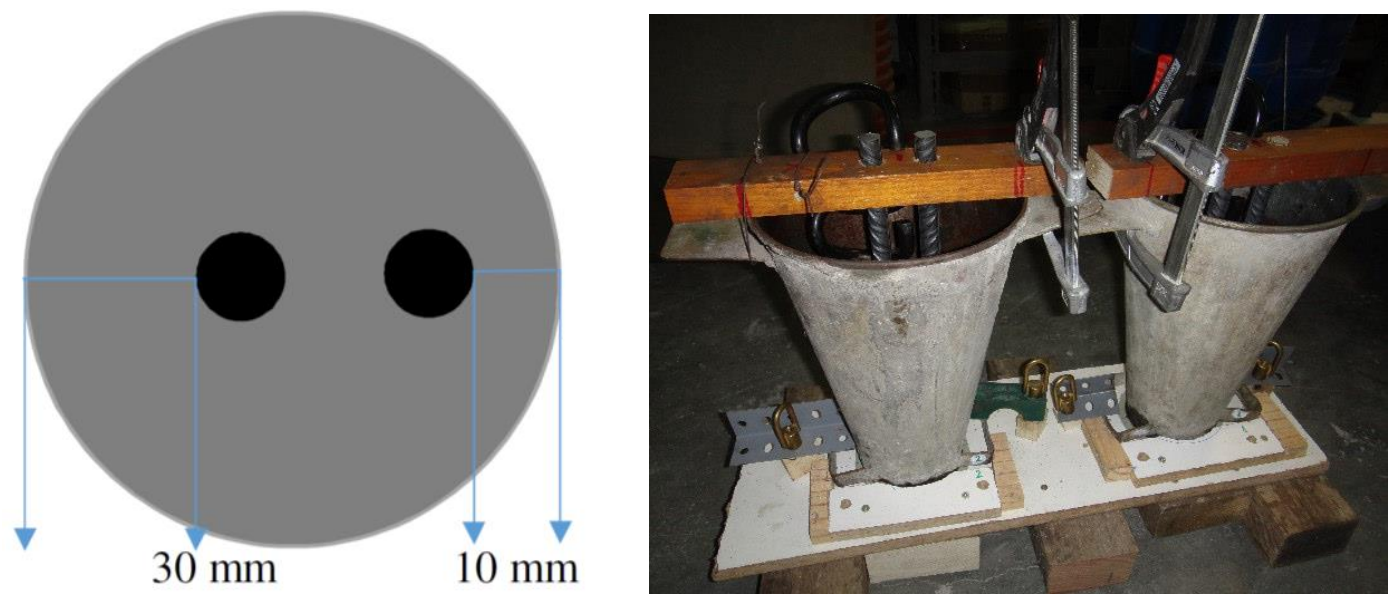

Figure 1. Arrangement of reinforcement bars on the underside of the cone and preparation of the truncated conical molds. 
To ensure that the penetration of chlorides only occurs in the lateral surface of the cone, the upper and lower faces have been protected, as well as the sections of corrugated bars that protrude from the concrete with a thick layer of two-component epoxy coating, Figure 2.
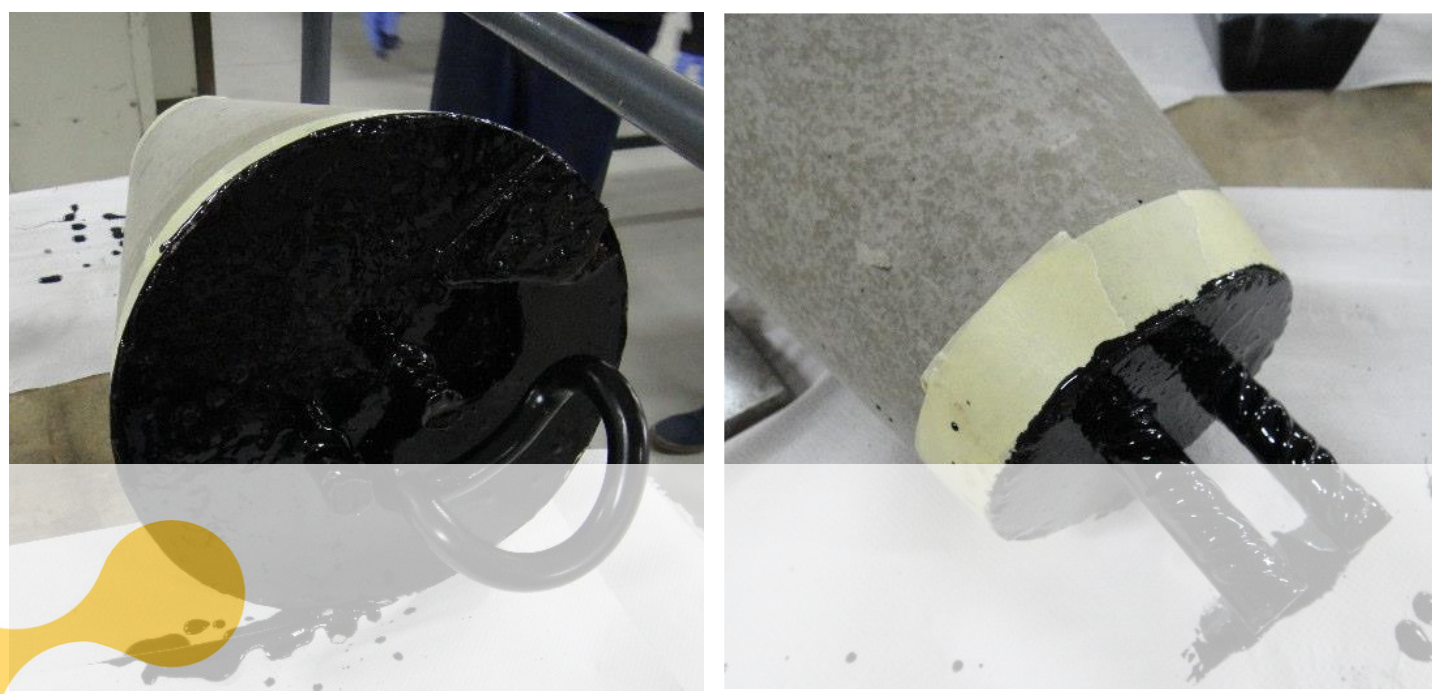

Figure 2. Detail of the application of the paint on the bases of the specimens and on the reinforcements.

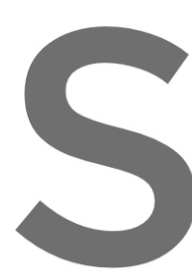

After keeping the transferred to the port of other specimens from o were suspended a few to tidal changes for 10 months, (Figure 3 right
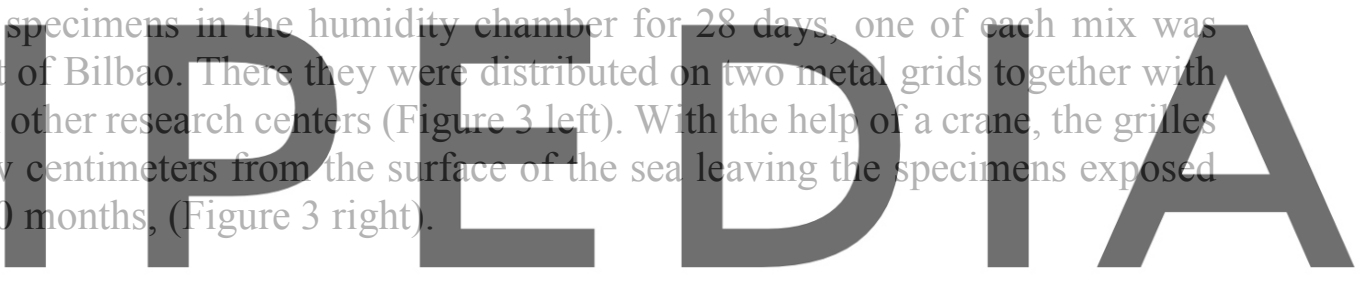

Register for free at https//www.scipedia.com to download the version without the watermark
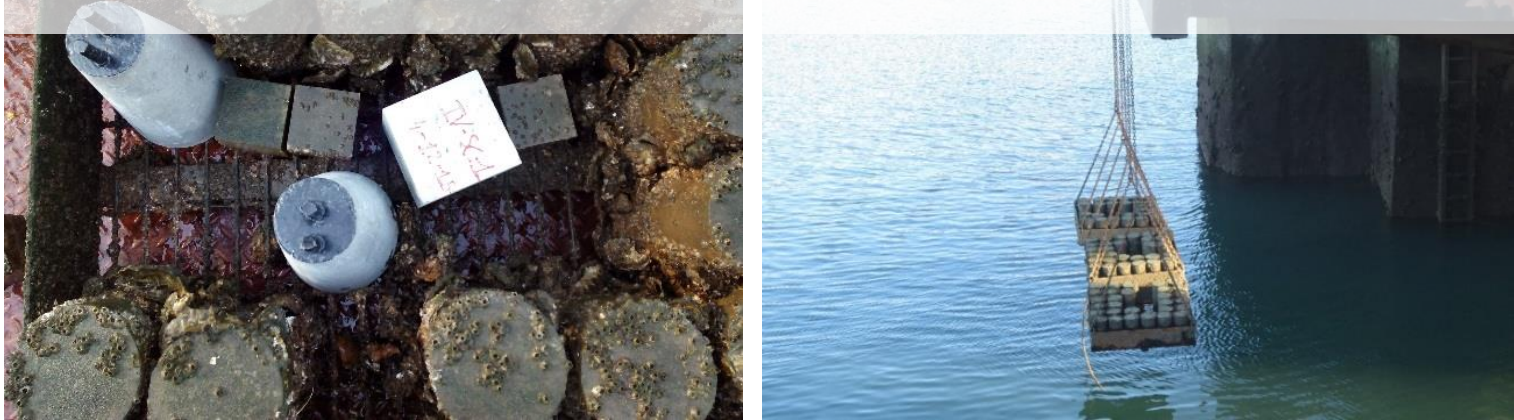

Figure 3. Arrangement and location of test samples in tidal race in the port of Bilbao.

\subsubsection{Specimens Treatment}

After 10 months, the specimens were removed and moved back to the laboratory. During the visual inspection, the abundant presence of mollusks adhered to the surface of the concrete specimens, the corrugated bars and the steel hook was observed (Figure 4). In the areas where 
these colonies were not present, the formation of an organic greenish layer was observed.

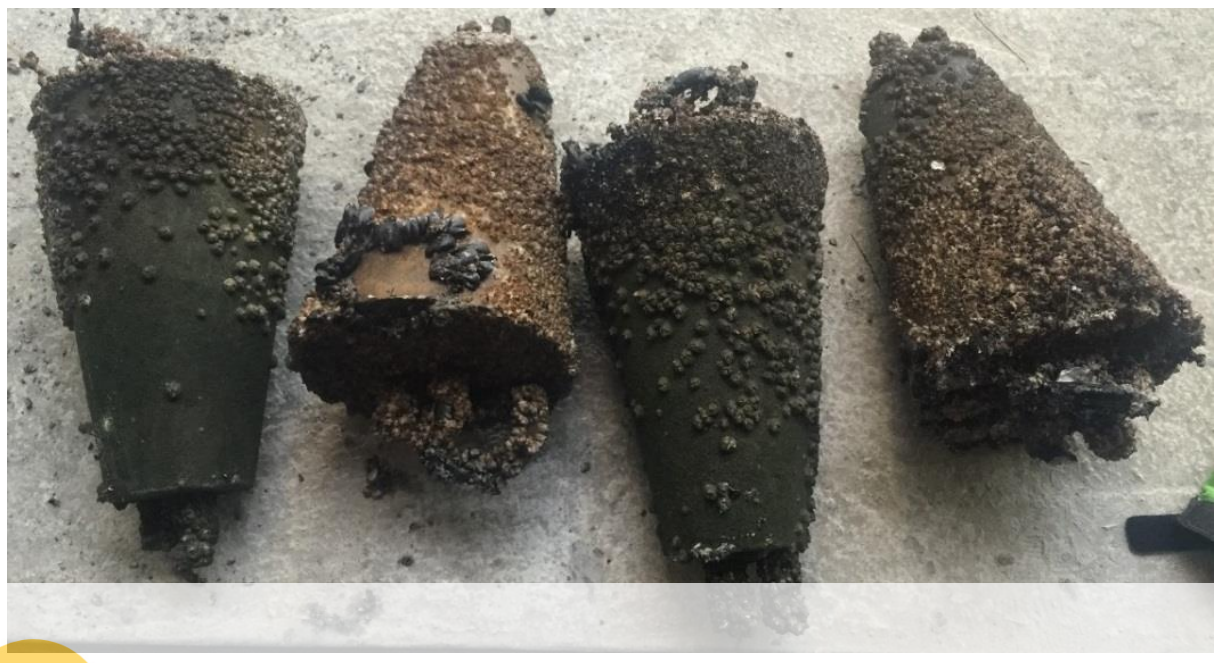

Figure 4. Appearance of the specimens after exposure to the weather and tidal cycles.

With the help of a crowbar, the mollusks stuck in the concrete were removed, while those attached to the bars and the metal piece were crushed with a hammer. The surface was then rubbed with a scourer to remove the organic layer (Figure 5). Finally, they were rinsed and

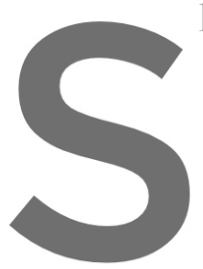
placed in the oven at
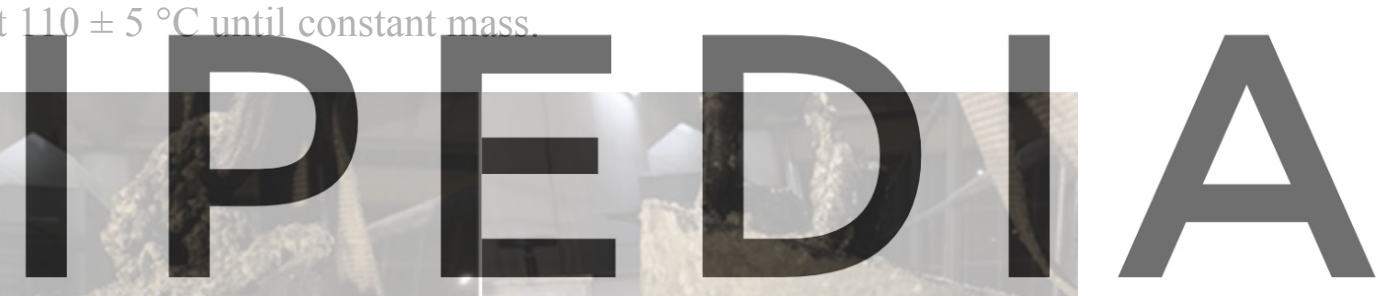

Register for free at https//www.scipedia.com to download the version without the watermark

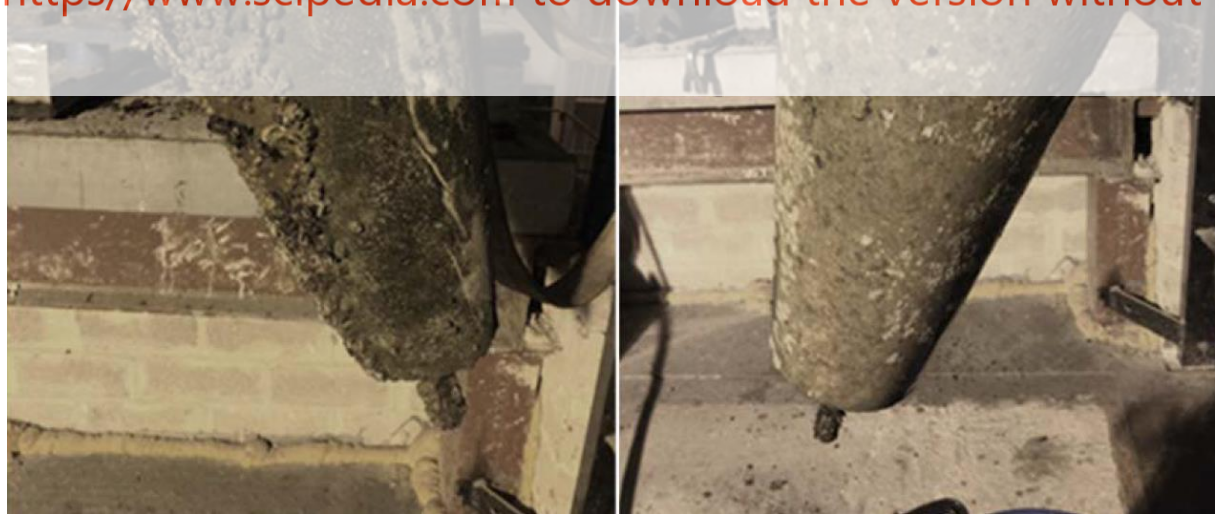

Figure 5. Appearance of samples before and after cleaning.

Finally, on each truncated conical specimen, two diametrically opposed longitudinal cuts were made with a radial cutter without the cutting disc reaching the corrugated bars. 


\subsubsection{Corrosion of the Bars and Penetration of Chlorine Ions}

After breaking the truncated concrete cone into two halves, we first proceeded to observe the state of the bars mainly to assess the appearance of pitting along them. One of the halves was divided by a cross-section in order to extract a subsample with different coating thicknesses, which is used to determine, in the scanning electron microscope, the penetration depth of the chloride ion by dispersive spectroscopy of X-rays (EDX) techniques.

\section{Results and Discussion}

Figure 6 shows the appearance of the specimens after continued exposure to the marine environment and to the tidal race for 10 months, after cleaning the exterior faces and the longitudinal cut.
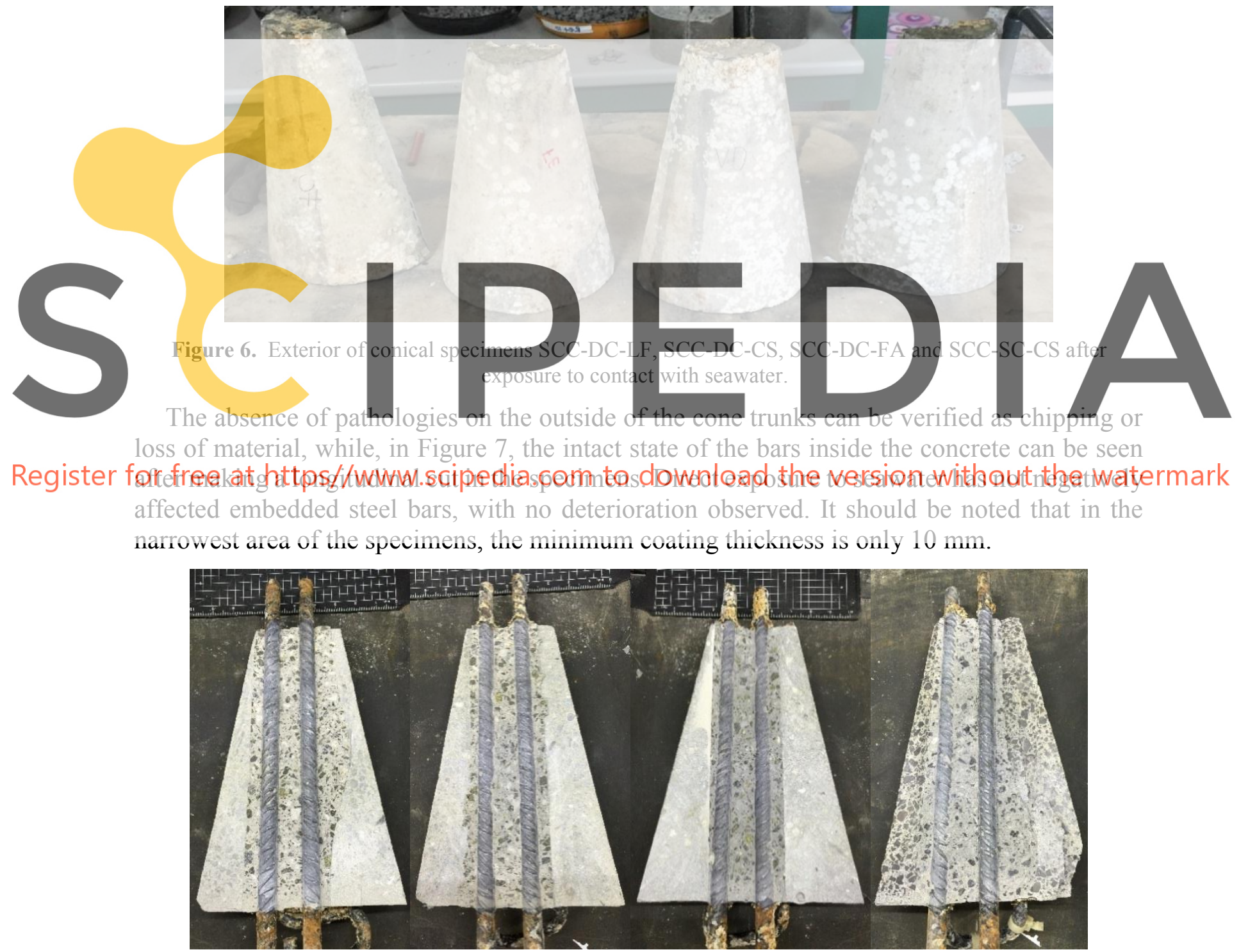

Figure 7. Inside of the SCC-DC-LF, SCC-DC-FA, SCC-DC-CS and SCC-SC-CS specimens after exposure to seawater. 
Figure 8 shows in detail the appearance of the steel bars at the narrowest end of the conical specimens for the SCC-SC-CS mix. In some cases, pitting corrosion is observed in the bars, caused by the penetration of seawater from the top of the specimen as a result of the loss of the applied waterproofing paint.

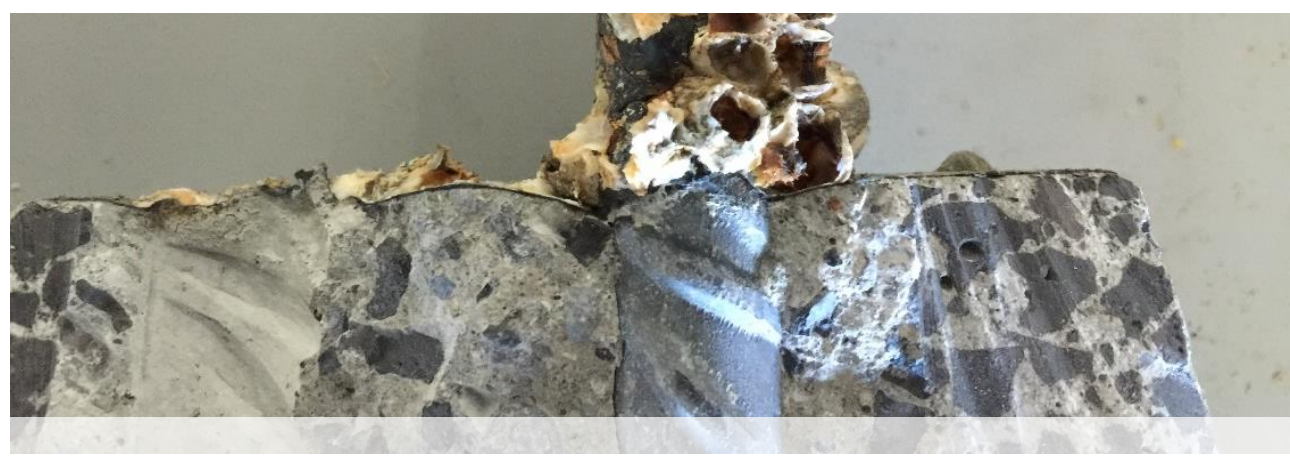

\section{Figure 8. Aspect of SCC-SC-CS and rebars after exposure to tidal race.}

Due to the appearance of the steel bars inside the concrete, the cut was only made at the smaller diameter end of the cone to determine the penetration of the chloride ion in a scanning electron microscope.

Figure 9 shows the chloride concentration in the concrete obtained by microanalysis carried out from the outermost expected, that the highes SC-CS has a much

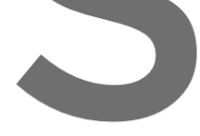
aggregates, despite contin
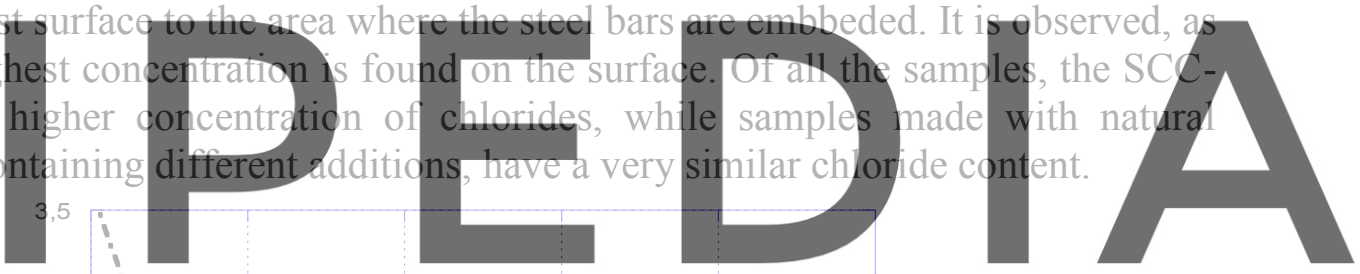

Register for free at https//www.scipedia.com to downloadthe version without the watermark

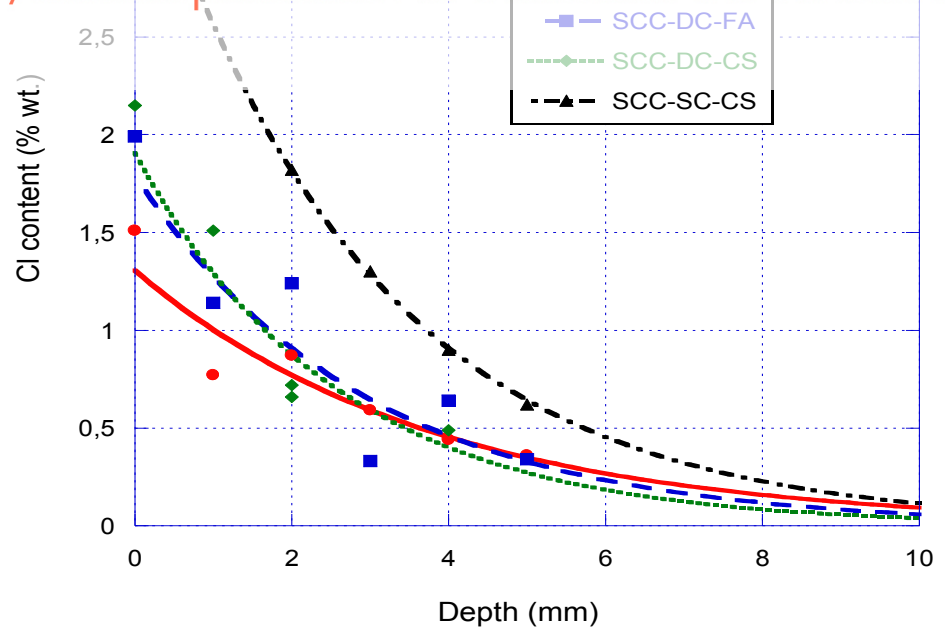

Figure 9. Penetration of chlorides in concrete.

These results agree with the oxygen permeability coefficients (Sosa et al., 2020), being able 
to assume that the diffusion is carried out through the capillaries. In all the cases analyzed, it can be seen that, after $6 \mathrm{~mm}$, the concentration of the $\mathrm{Cl}^{-}$ion is less than $0.3 \%$, which is at the limit of the detection capacity of the scanning electron microscope for this element. These results are markedly lower to those reported by C. Medina et al. for a CVC with recycled aggregates (Medina, Sánchez De Rojas, Thomas, Polanco \& Frías, 2016).

\section{Conclusions}

In the present study, the durability of 4 concrete mixes incorporating aggregates and admixtures, both slag and natural, has been analyzed. This characterization has been carried out keeping the specimens in a tidal race, where both the marine environment and the submersion cycles can deteriorate the material prematurely. The main conclusion drawn is the following:

Exposure to seawater and the tidal race for 10 months has not affected the aesthetics, nor has it corroded steel reinforcements embedded in concrete. The concentration of chlorides in all cases is very small from $6 \mathrm{~mm}$ deep.

\section{ORCID}

Israel Sosa: https://orcid.org/0000-0003-1087-0838

Carlos Thomas: https://orcid.org/0000-0002-2641-9411

Juan Antonio Polanco: https://orcid.org/0000-0002-2649-9490

Jesús Setién: https://orcid.org/0000-0002-6285-8745

Pablo Tamayo: https://orcid.org/0000-0003-2195-7883

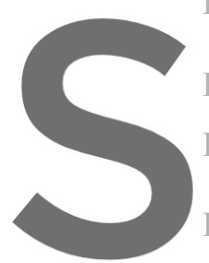

References

De Schutter, G. and Audenaert, K. RILEM Technical Comm

Dinakar, P., Sethy, K. P. and Sahoc, blast furnace slag. Materials \& Design, 43(0), 161-
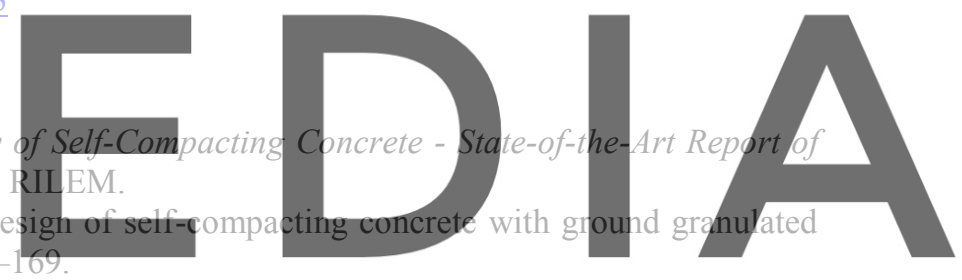

E. Medina, D. M. B. (2013). Armaduras de acero inoxidable (1st ed.). CEDINOX.

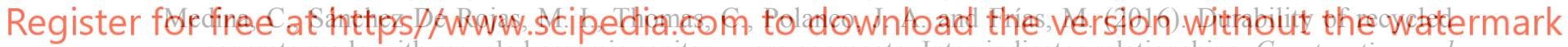
concrete made with recycled ceramic sanitary ware aggregate. Inter-indicator relationships. Construction and Building Materials, 105. https://doi.org/10.1016/j.conbuildmat.2015.12.176

Ministerio de Fomento de España, (2008). EHE-08: Instrucción de Hormigón Estructural. Retrieved from: http://www.fomento.gob.es/MFOM/LANG_CASTELLANO/ORGANOS_COLEGIADOS/CPH/instruccione s/EHE08INGLES/

Sosa, I., Thomas, C., Polanco, J. A., Setién, J. and Tamayo, P. (2020). High Performance Self-Compacting Concrete with Electric Arc Furnace Slag Aggregate and Cupola Slag Powder. Applied Sciences, 10(3), 773.

Thomas, C., Cimentada, A., Polanco, J. a., Setién, J., Méndez, D. and Rico, J. (2013). Influence of recycled aggregates containing sulphur on properties of recycled aggregate mortar and concrete. Composites Part B: Engineering, 45(1), 474-485. https://doi.org/10.1016/j.compositesb.2012.05.019

Uysal, M. and Yilmaz, K. (2011). Effect of mineral admixtures on properties of self-compacting concrete. Cement and Concrete Composites, 33(7), 771-776. https://doi.org/10.1016/j.cemconcomp.2011.04.005

Zhu, W. and Bartos, P. J. M. (2003). Permeation properties of self-compacting concrete. Cement and Concrete Research, 33(6), 921-926. https://doi.org/10.1016/S0008-8846(02)01090-6 